\title{
Vertical-Cavity Surface-Emitting Lasers: Design, Growth, Fabrication, Characterization
}

\author{
Jack L. Jewell, J. P Harbison, A. Scherer, Y. H. Lee, and L. T. Florez
}

\begin{abstract}
We have designed, fabricated, and tested verticalcavity surface-emitting lasers (VCSEL) with diameters ranging from $0.5 \mu \mathrm{m}$ to $>50 \mu \mathrm{m}$. The approaches we have taken have produced (not necessarily by us) the smallest, the lowest threshold, the highest quantum efficiency, and the highest modulation speed VCSEL's to date. The four principal sections of this paper-design issues, molecular beam epitaxial growth, fabrication, and lasing characteristics-are written by people who are closely involved in their development.
\end{abstract}

\section{INTRODUCTION}

$\mathrm{V}$ ERTICAL-CAVITY surface-emitting lasers (VCSEL) have optical cavities orthogonal to those of conventional edge-emitting diode lasers [1]. This simple change in the cavity orientation produces radical differences in the beam characteristics, scalability, optoelectronic design, fabrication, and array configurability. For example, VCSEL's typically emit circularly symmetric Gaussian beams in contrast to the astigmatic beams of edge emitters, and thus require no anamorphic correction. The smallest electrically pumped VCSEL's to date have active material volumes $<0.05 \mu \mathrm{m}^{3}$, an order of magnitude less than the smallest edge emitter [2], and optically pumped VCSEL's are as small as $0.002 \mu \mathrm{m}^{3}$ active volume. Electrical pumping in VCSEL's is, so far, not nearly as efficient as in edge emitters, because all demonstrated designs have compromised between optical and electronic characteristics. For this reason, edge emitters currently have a clear edge in high-power applications. VCSEL fabrication techniques differ widely depending on the laser size and, for example, whether or not a two-dimensional addressable array is being built. A two-dimensional addressable array is a configuration well suited for VCSEL's but extremely impractical for edge emitters. These widespread differences virtually assure each type of laser a portion of the diode laser market.

VCSEL's were pioneered by Iga et al. at the Tokyo Institute of Technology [3]. Starting in the late 1970's with an electrically pumped laser operating at $77 \mathrm{~K}$ emitting $1.2 \mu \mathrm{m}$ wavelength [1], they later produced the first VCSEL arrays [4], devices with reasonably low thresholds [5], the first room-temperature CW VCSEL [6], and

Manuscript received November 14, 1990; revised February 26, 1991. J. L. Jewell and Y. H. Lee are with AT\&T Bell Laboratories, Holmdel, NJ 07733.

J. P. Harbison, A. Scherer, and L. T. Florez are with Bellcore, Red Bank, NJ 07701 .

IEEE Log Number 9100201. the first linewidth measurements of CW VCSEL's [7]. Industrial adoption of this technology produced the first lowthreshold room-temperature CW VCSEL [8]. The VCSEL's in our work evolved from all-optical GaAs nonlinear Fabry-Perot etalons originally designed for optical bistability [9] and switching at Bell Laboratories, also in the late 1970's. Starting with films of GaAs a few microns thick and coated with dielectric mirrors [10], the work pushed toward higher finesse cavities and thinner active material [11], all-molecular-beam-epitaxially grown structures [12], and waveguiding microresonators [13], [14] with submicron lateral dimensions [15] and device densities $>10^{7} / \mathrm{cm}^{2}$. The addition of dopants and electrical contacts to this kind of structure produced more than one-million low-threshold VCSEL's on a single GaAs chip [2], [16]-[19].

This paper contains four principal sections-design issues, epitaxial growth, fabrication, and performance characteristics-written by the first four coauthors, respectively. We attempt to make it as generally applicable as possible, but we are naturally inclined toward the techniques and devices we have produced. Applications issues have necessarily been left out to maintain reasonable length.

\section{Design Issues}

A generic VCSEL is shown in Fig. 1. If the active material is a single quantum well (SQW) of GaAs, 100 $\mathrm{A} / \mathrm{cm}^{2}$ or more is required to reach transparency [20], especially in small-area devices. For $N$ wells, or for bulk material of thickness $N$ times $10 \mathrm{~nm}$, the minimum transparency current density is about $N$ times $100 \mathrm{~A} / \mathrm{cm}^{2}$. Acceptable threshold current densities $\left(<1 \mathrm{kA} / \mathrm{cm}^{2}\right)$ thus imply an active region of thickness less than $\sim 100 \mathrm{~nm}$. In GaAs lasers, one period of the standing wave field is $\sim 120 \mathrm{~nm}$, so a $100 \mathrm{~nm}$ thick layer would be partly wasted by having portions of it in regions of very low optical intensity. Thus, we have restricted our GaAs VCSEL designs to those having active region thicknesses of about $60 \mathrm{~nm}$ or less, or more generally, less than one-quarter wave in the material (Fig. 2). Since the active region is necessarily semiconductor material grown by epitaxial techniques, high-quality $\mathrm{p}-\mathrm{n}$ junctions are easily produced in the vertical orientation, while they are very difficult to obtain horizontally [21], [22]. Thus, a thin active layer, narrow $\mathrm{p}$-i-n structure facilitates a low-resistance active region having low current density requirements. 


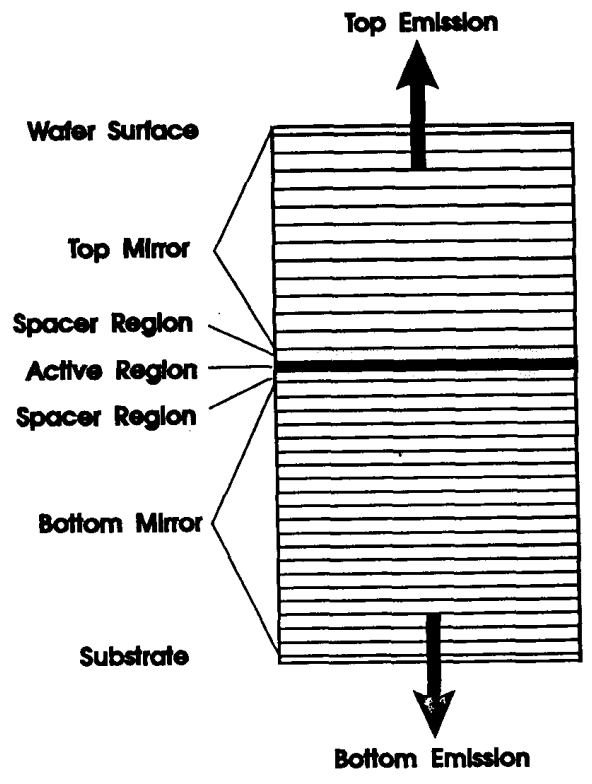

Structure

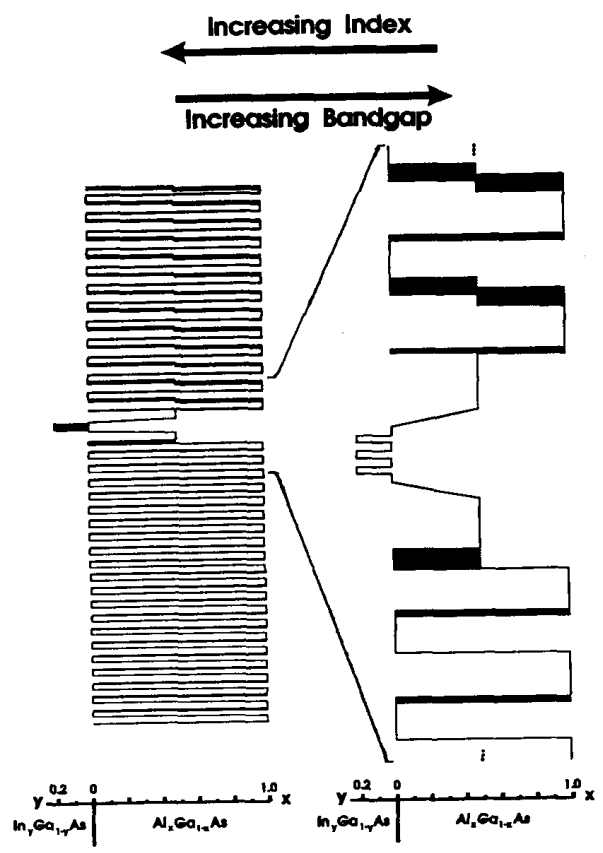

Composition

Fig. 1. Schematic representation of a vertical-cavity surface-emitting laser, shown on the left, together with the compositional layer structure used in an actual device indicate sections of rapidly alternating layers, inserted to assist current flow across otherwise abrupt heterojunctions.

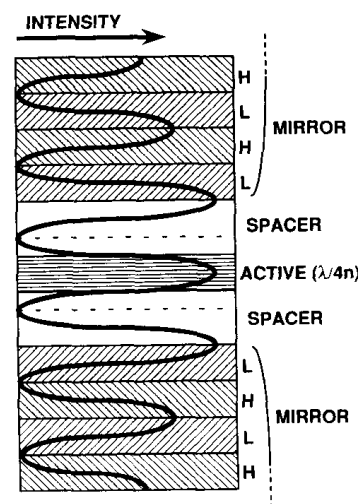

Fig. 2. Standing wave intensity distribution in the central region of a VCSEL. The active region thickness shown is one-quarter of the operating wavelength $\lambda$, divided by the refractive index $n . H$ and $L$ denote high and low index layers, respectively, of the mirror.

Since the gain per pass of such an active region is on the order of $1 \%$ [20], mirror reflectivities greater than $99 \%$ are required. So far, the lowest threshold VCSEL's employed a single quantum well (SQW) of InGaAs active material [17], [23], [24]. Periodic gain structures [22], [25] can accommodate arbitrarily large thickness by placing active layers in the high-intensity lobes, but a rather long cavity results in which longitudinal current flow would generally encounter high resistivity. Top-surface emitting lasers [25], [27]-[30] emit light through a window in the top electrode, and have exhibited the highest room-temperature $\mathrm{CW}$ powers to date.

The mechanism desired for achieving confinement of the electrical current and optical field depends on the laser's transverse dimension. VCSEL's of diameter $10 \mu \mathrm{m}$ or more are desirable when ultralow threshold is not required; gain guiding is sufficient and has been achieved by ion implantation [26]-[31]. This has the attractive feature of preserving planarity in the wafer. Submicron diameters, on the other hand, require strong optical waveguiding such as that obtained by etching vertically throughout the optical resonator. Otherwise, diffraction losses are too high to allow lasing. Such devices may find uses in optical switching or interchip communication where high speed and low power are absolutely necessary. Their performance may be further enhanced by the microcavity's effect on the spontaneous emission. For diameters $\sim 3-10 \mu \mathrm{m}$, a combination of gain guiding and waveguiding can be used in a continuously variable fashion which corresponds well with calculations of diffraction loss [18].

Maximum power obtainable from a single device depends largely on the cooling capability and the power efficiency $P_{\text {eff }}$. The latter can be expressed in terms of the 
differential quantum efficiency $\eta_{\mathrm{eff}}$, threshold current $I_{t h}$, operating current $I_{o p}$, lasing photon "voltage" $V_{g}$ (basically the bandgap energy in $\mathrm{eV}$, normalized by the electron charge), and series resistance $R$, as

$$
P_{\mathrm{eff}}=\eta_{\mathrm{eff}} \cdot \frac{\left(I_{o p}-I_{t h}\right)}{I_{o p}} \cdot \frac{V_{g}}{\left(V_{g}+I_{o p} R\right.}
$$

assuming the classical $L-I$ curve with zero output at threshold and a constant slope, $\eta_{\text {eff }}$, above threshold. The product of all three numerators is the output power. The second factor of (1) illustrates the necessity of operating far above threshold for power efficiency. The denominator of the third factor is simply the operating voltage drop across the device. It shows explicitly that series resistance is not the sole indicator of electrical efficiency. For example, scaling devices to larger areas decreases $R$, but the larger currents required can result in a similar voltage drop and therefore no significant change in efficiency. A more relevant quantity for expressing a diode laser's electrical performance is the voltage required for threshold. Obtaining high $P_{\text {eff }}$ in VCSEL's and edge emitters is the same: minimize resistivity and threshold current density, and provide effective heat removal.

Assuming that $P_{\text {eff }}$ is sufficiently high so that cooling is achievable, the maximum power is determined by the maximum internal intensity allowable and the maximum cross-sectional area for single-mode operation. Reasonable, but certainly not ultimate, values for these are $10^{7}$ $\mathrm{W} / \mathrm{cm}^{2}$, and $200 \mu \mathrm{m}^{2}$ (16 $\mu \mathrm{m}$ diameter), based on our experiments together with data for commercially available edge emitting lasers. Assuming a $1 \%$ transmitting output coupler, this yields about $200 \mathrm{~mW}$ maximum power. It is tempting to increase this by using a lower reflectivity output coupler; that, however, implies an increase in the active material thickness. That increased thickness will increase $I_{t h}$, thus increasing current and cooling requirements which may well not be achievable. A more promising approach is to increase the single-mode diameter by increasing the cavity length with nonactive material. Due to light penetration into the mirrors, allsemiconductor AlGaAs-based VCSEL's have a minimum effective cavity length of about $1 \mu \mathrm{m}$ [32]. Adding $1 \mu \mathrm{m}$ to this should approximately double the cross-sectional area for single-mode operation and therefore double the maximum power, ignoring effects such as thermal lensing caused by temperature variations across the device. However, adding doped material increases the cavity loss, which decreases efficiency. Using undoped material requires transverse current flow and the voltage drop increases, thereby also decreasing efficiency. Thus, this approach may be rather limited as well. Pulsed peak powers as high as $120 \mathrm{~mW}$ have been reported from $\sim 35 \mu \mathrm{m}$ diameter thick cavity VCSEL's with high current densities [33].

Our designs for VCSEL active regions are usually graded-index separate-confinement heterostructure
(GRINSCH) structures, very similar to the $\mathrm{p}-\mathrm{i}-\mathrm{n}$ diodes of edge emitters. Thus, the active region resistivities should be comparably low. The excessive resistance in VCSEL's is between the contacts and the active region. Resistance in p-type mirrors is high, largely due to the periodic potential well/barrier structure of the AlGaAs-AlAs. This has been minimized by using nonabrupt interfaces [2], [23], [27]-[30], (34), and/or keeping the maximum difference in $\mathrm{Al}$ content to be less than about 60\% [34]-[36]. The latter strategy increases light penetration into the mirrors, increasing the round-trip loss in the cavity which can seriously decrease efficiency for very thin active regions. For n-type mirrors, the resistance is somewhat less than for optimized GaAs-AlAs p-type mirrors, and is believed to be caused mostly by the poor conductivity of AlAs. Devices of diameter $\geq 5 \mu \mathrm{m}$ can employ current spreading in either or both mirrors to decrease $R$. Use of all these techniques still has not produced VCSEL's with threshold voltages $V_{t h}$ much lower than $3.5 \mathrm{~V}$. The lowest reported $V_{\text {th }}$ in a VCSEL is $1.8 \mathrm{~V}$, achieved by using silver as the only reflector for the p-side [37]. The Ag-AlGaAs reflectivity of only $\sim 95 \%$ implied a thick active layer, thus high current density, and also low overall efficiency. Presently, the approach offering the most hope for power efficient VCSEL's has current flow transversely through highly conductive layers just above and below the active region, and vertically through the junction. As a final point of the resistance issue, conventional designs for very small lasers (of any sort) will produce very high resistance. Efficient edge emitters can have $R=2-5 \Omega$ over areas about $500-200 \mu \mathrm{m}^{2}$. Scaling them down to $1 \mu \mathrm{m}^{2}$ would lead to $R \sim 1 \mathrm{k} \Omega$.

Ultralow threshold $(<100 \mu \mathrm{A})$ in diode lasers implies very small volume of active material. VCSEL's are very straightforwardly scalable to volumes on the order of $0.002 \mu \mathrm{m}^{3}$ (SQW in a $1 / 2 \mu \mathrm{m}$ diameter), but fabrication becomes quite challenging. Surface recombination is a serious problem for small-diameter GaAs VCSEL's, and steps are being taken to reduce or eliminate it [38], [39]. For InGaAs devices at $1.3-1.55 \mu \mathrm{m}$, the recombination velocity is about 100 times less [40]. GaAs-AlAs waveguides $\leqslant 1 \mu \mathrm{m}$ in diameter also exhibit waveguide dispersion which shift the cavity resonant wavelength by $\sim 50 \mathrm{~nm}$ at $0.5 \mu \mathrm{m}$ diameter [15]. This means that devices in this size range must first be designed with thicker layers to compensate for the shift, then fabricated with strict tolerances on the diameter. The reward for such fabrication may be much more than simply a smaller volume. The spontaneous emission factor of the fundamental mode (SEF, which is the fraction of spontaneously emitted photons which couple into the laser cavity's fundamental mode) can approach unity for such devices, compared to SEF's of $10^{-4}-10^{-5}$ in conventional lasers [41]. Microcavities can even enhance the rate of spontaneous emission into the lasing mode, while suppressing emission in other directions [42], [43]. This could lead to extremely fast, efficient devices with thresholds on the order of 10 $\mathrm{nA}$. Nontraditional current injection schemes such as real 
space transfer [44] may offer fast, efficient means for driving such devices.

It is advantageous from many standpoints to have the entire VCSEL structure (except for electrical contacts) be a single crystal grown by techniques such as molecular beam epitaxy (MBE) or metal-organic chemical vapor deposition (MOCVD). Mechanical and optical quality are very high, thermal conductivity is good, and the number of fabrication steps is minimized. The materials available for this kind of structure are severely restricted, however, and are generally limited to semiconductors whose lattice constants do not vary greatly, and whose chemical properties are compatible. For GaAs VCSEL's, the obvious choice for mirrors is AlAs-AlGaAs quarter-wave stacks. Since these materials have refractive indexes about $3.0 / 3.5$, it takes $20-30$ periods to produce $99.9 \%$ reflectivity, and VCSEL structures are typically 5-6 $\mu \mathrm{m}$ thick. This takes a full day's growth by MBE. Furthermore, the thickness accuracy is about $\pm 1 \%$, assuming a gain bandwidth about $1 \%$ of the optical frequency and a short cavity. This accuracy is about the limit of current state-ofthe-art MBE systems. For $1.55 \mu \mathrm{m}$ VCSEL's, the situation is much worse. "Convenient" materials (in this case, not containing $\mathrm{Sb}$ ) available have a refractive index difference only $\sim 0.2-0.3$, so about twice as many pairs are needed as for AlAs-AlGaAs [45], [46]. Each layer must also be about twice as thick so the total VCSEL thickness would be $>20 \mu \mathrm{m}$. Alternatively, one or both mirrors can be dielectrics. Fabrication becomes more complicated, but layers of widely differing refractive indexes, e.g., $\mathrm{SiO}_{2}$ Si [47], [48], can be used to make shorter faster cavities in which spontaneous emission properties may even be enhanced [49]. Use of in situ optical monitoring during dielectric film deposition routinely produces thickness accuracies much less than $1 \%$. Practical VCSEL's at 1.3$1.55 \mu \mathrm{m}$ will very probably have dielectric mirrors; at shorter wavelengths, the tradeoffs are more even. If at least one of the mirrors is epitaxial, a tremendous advantage for processing is gained by not having to remove the substrate.

\section{Growth}

One unique feature of these latest vertical-cavity structures is that both the central light-emitting GRINSCH region and the outermost Bragg reflectors which define the Fabry-Perot cavity are all dimensionally defined in one integrated crystal growth sequence performed over the entire wafer using molecular beam epitaxy (MBE). The details of one such typical structure are shown in Fig. 1, illustrating the use of carefully controlled layer structures achieved by MBE in the formation of many of the key elements in the device including the active layer quantum wells, graded confinement barriers, spacer layers, alternating index Bragg reflectors, and graded short period superlattice structures between mirror layers to promote carrier transport. The high lateral thickness uniformity achievable in a modern MBE growth system ensures that if the design parameters are properly met at one point on the wafer, they will carry over to within about $1 \%$ uniformity across the entire wafer employing substrate rotation to achieve this high level of uniformity. This leads to extremely high yields (in excess of $99 \%$ ) and, perhaps even more importantly, high uniformity in individual device characteristics across large two-dimensional arrays, which is of vital importance in most array applications.

Achieving this high degree of precision places severe demands on the MBE growth process. The realization of the proper emission wavelength from the central $\mathrm{In}_{y} \mathrm{Ga}_{1-y} \mathrm{As}$ quantum wells through growing the proper quantum well thickness and indium concentration, $y$, is demanding, but no more so than in an edge-emitting laser which must be properly grown to operate at a specific wavelength. What makes the growth task so much more difficult in the case of an integrated semiconductor-mirror vertical-cavity structure is the extremely tight demands on the layer thicknesses of the mirror layers. As discussed in the previous section, because the length within the cavity over which gain is achieved is so much shorter for a vertical-cavity design than it is for an edge emitter, the mirrors need to be of exceedingly high reflectivity, typically in excess of $99 \%$. Since the partial reflection at each AlAs-GaAs interface in the Bragg reflector is only about $0.6 \%$, many such interfaces need to be stacked together in order to achieve the desired high overall stack reflectivity. In order to achieve this high reflectivity, each repeated layer in the stack must be nearly the same as the others in order to get the proper constructive interference between all the layers. This high degree of periodicity, however, is relatively straightforward to obtain in an epitaxial growth technique such as MBE through the use of precise repetitive shutter timing from period to period, as long as sufficient attention has been given to keeping the effusion cell source stability and hence growth rate stability under tight control for the relatively long periods of $8-12 \mathrm{~h}$ required to grow these structures.

The cavity resonances for these high-finesse FabryPerot cavities are very narrow, typically $\leq 0.01 \%$ of the optical frequency, essentially a delta-function for our purposes here. The requirement that the spectral position of this resonance fall within the relatively narrow $1 \%$ wide gain region of the active quantum wells places a severe constraint on the optical thicknesses of the layers making up the cavity. Not only does this requirement demand an exact knowledge of the alloy concentration, since the optical index is composition dependent, even more stringently, it demands absolute growth rate control to within $1 \%$. Only by knowledge and control of the semiconductor growth rate determined for each of the group III components to within this $1 \%$ tolerance is it possible to meet these stringent requirements. The remainder of this section of the paper will discuss in detail how MBE has been used to achieve this necessary high level of control. Although for clarity we will concentrate on the $980 \mathrm{~nm}$ strained InGaAs quantum well structures, most of the specific issues discussed apply equally well to other similar 
designs, including the $850 \mathrm{~nm}$ GaAs quantum well devices which are also included later in the characterization section of this paper.

The MBE growth system we have used is a Varian GEN II configured to accept 2 -in diameter indium-bonded GaAs substrates. The eight effusion cells employed consist of 1) four upward-looking $16 \mathrm{cc}$ cells for the group III elements (In, Ga, and two Al) designed by Varian with trumpetshaped crucibles for high uniformity across the entire substrate; 2) two cells (also the $16 \mathrm{cc}$ design, prepared for downward-looking operation as previously described by Collins [50] containing the n- and p-type dopants, Si and $\mathrm{Be} ; 3)$ one $40 \mathrm{cc}$ downward-looking $\mathrm{As}_{4}$ cell employing a seven-hole boron nitride end cap; and 4) a downwardlooking two-zone Varian cracker cell for supplying $\mathrm{As}_{2}$. Surface emitting laser structures have been grown using each of the two alternative arsenic sources, $\mathrm{As}_{4}$ and $\mathrm{As}_{2}$, with no systematic differences in the resulting devices. One modification made to the system to eliminate the rather large flux transients recorded using the beam flux ionization gage when the group III sources were opened was the addition of double-sided 4.5-in conflat flanges on each of the $16 \mathrm{cc}$ cell ports to bring them back away from the shutters, thus minimizing the closed-shutter overheating known to cause the transient effect. This was found to drop the transient, which has a time constant of approximately $1 \mathrm{~min}$, from the $20 \%$ range down to a reasonably small and reproducible value of $4 \%$.

The most important part of the process used to achieve the $1 \%$ thickness control discussed earlier is the careful monitoring of oscillations in the intensity of the specularly reflected spot of the reflection high energy electron diffraction (RHEED) pattern. Neave et al. [51], as well as others, have shown quite elegantly how each oscillation corresponds to precisely one monolayer of deposition. By carefully measuring this period, the exact growth rate can be determined. The data acquisition system we employ involves an optical fiber butted up to the portion of the RHEED screen containing the specular spot, coupled on the other end to a photomultiplier tube. The amplified current output of the photomultiplier is digitized approximately 20 times/s and fed through a CAMAC interface into a micro-PDP 11 computer where it is analyzed in software. After a five-point smoothing routine is performed on the data, the maxima and minima are determined and a section of adjacent periods, usually numbers $2-12$, are measured, and a resulting rate is calculated, taking into account the $4 \%$ flux transient correction discussed above.

One key issue in getting reliable $1 \%$ control of rates comes in the reevaporation of the more volatile group III species during growth above a certain critical temperature (In in the case of InGaAs and $\mathrm{Ga}$ in the case of AlGaAs). Although, in principle, RHEED oscillations measure not just the group III arrival rate but the actual growth rate consisting of that arrival rate less the reevaporation rate, this reevaporation rate is strongly substrate temperature dependent. Since the RHEED oscillation calibrations are performed prior to the actual growth on a small test sample centrally mounted on a different Mo sample block, any differences in the actual surface temperature, a quantity which is in general very difficult to measure accurately, will result in different reevaporation rates for the RHEED test sample and the actual wafer. The differences become more pronounced at higher substrate temperatures. It is for this reason that we have chosen in these structures the requirement of such a high degree of precision to remain in the substrate temperature regime where such reevaporation effects are negligible on the scale of $1 \%$. This means growing the GaAs-AlGaAs-AlAs layers at $580^{\circ} \mathrm{C}$ and the InGaAs at $530^{\circ} \mathrm{C}$, determined by substrate thermocouple readings calibrated for each run to the known oxide desorption temperature of $580^{\circ} \mathrm{C}$. Admittedly, this is a compromise, trading off optimal crystal quality attainable at higher substrate temperatures against higher rate control attainable at lower temperatures. As better forms of substrate temperature measurement become available, this compromise will become less severe.

Staying in the negligible group III reevaporation regime has the added advantage that the requirements of exact timing of substrate temperature changes and the need to return to precisely the same substrate temperatures are made much less stringent. This is not true, however, of cell temperatures, as will be discussed below. The use of relatively thin AlGaAs ternary alloy layers, coupled with the frequent use of short period superlattices, helps avoid rough interface problems resulting from low substrate temperatures, which is highly undesirable in high-reflectivity structures such as these. These issues become more severe in shorter wavelength VCSEL structures employing GaAs (rather than InGaAs) active layer quantum wells, because in such structures the dielectric stacks become AlAs-AlGaAs rather than AlAs-GaAs, exacerbating this smooth growth problem [52].

Using the above methodology, the rates of each of the $\mathrm{Ga}$ and $\mathrm{Al}$ cells is measured at least three times, allowing at least 2 min between each measurement for the $4 \%$ flux transient to be reproducibly reestablished. If the three values do not lie within a few percent of each other, the measurements are repeated. For the case of InAs, which severely lattice mismatched with the GaAs RHEED sample and hence will not grow pseudomorphically long enough to get a sufficient number of RHEED oscillations, the rate of InGaAs is measured directly by observing oscillations on simultaneously opening the In and Ga shutters. Once all the rates have been measured in the manner just described, small adjustments are calculated for the cell setpoints based on previously determined Arrhenius plots for each cell, and the cell temperature adjustments are made. After equilibration times of at least $15 \mathrm{~min}$ for the cells to adjust, the measurement process is repeated. This entire cycle is repeated as many times as necessary to arrive at calibrated growth rates within the $1 \%$ tolerance required.

Some final comments are in order on three important requirements for the growth of these structures. The first 
two requirements-shutter reliability and thickness uniformity across the entire wafer-are a function of the particular MBE system used. They are both primary concerns of the MBE manufacturers when they design their systems, but it is worth pointing out that the demands imposed by the surface emitting laser structures discussed here $(1 \%$ uniformity and up to 1000 shutter operations per wafer) are severely pressing those manufacturer's designs to the limit, and can only be attained in an optimized stateof-the-art MBE growth system. The third requirement, that of cell flux stability, has components tied both to the manufacturer and the user. The requirement that the RHEED determined rate, determined at the beginning of the day, hold constant to within $1 \%$ over the remaining $8-12 \mathrm{~h}$ of the subsequent growth run is a rather stringent design specification to put on a cell/temperature controller combination, but our favorable results in growing these structures indicate that this design need has in fact been met by the manufacturer. What we have done as a user to further ensure this constancy is to hold the cells at constant temperatures throughout the growth run once the RHEED calibrations have been performed. Changing a cell temperature in the middle of a run to achieve a different alloy concentration, and then changing it back to continue at the nominal starting rate, does work to within a few percent, absolute, but is most likely a risky business in achieving the desired $1 \%$ reproducibility. It is for this reason that when growing these structures we calibrate at the beginning of each day (the cells are idled a few hundred degrees cooler overnight) and hold the cell temperatures constant thereafter. Extra combinations of alloy concentrations are then achieved by the use of multiple cells (two Al cells in our case) and by the use of short period superlattice chopping to achieve different average concentrations. It is also by means of this latter technique that any graded regions are introduced into the sample. In this way, the necessary high precision required in these structures can be achieved and maintained.

\section{Fabrication of Vertical-Cavity Surface- EMITTING LASERS}

Vertical cavity devices, such as microlasers, are ideally suited for integration into large numbers of nearly identical low-threshold array elements. Through the application of lithographic techniques and ion processing, the diameters of individual microlasers have been reduced to below $1 \mu \mathrm{m}$. The accompanying reduction in active volume can be used to further decrease the threshold currents required to operate these microlasers, and permits us to combine them into more complex, coherently coupled arrays. In this section, we describe the techniques which we have employed so far to fabricate surface-emitting microlasers; these currently involve ion etching and/or ion implantation. We also describe methods of packaging these devices into large arrays, and discuss the limitations to their further miniaturization and threshold reduction imposed by our present fabrication tools.

\section{A. Microlaser Geometries}

Conceptually, the simplest method of defining a vertical-cavity device from a grown wafer relies on the physical removal of the material everywhere except for the cavity itself. This is typically accomplished by masking the shape of the laser, and etching away the unwanted semiconductor by using either a suitable chemical solution of a reactive ion process [19]. We thereby transfer the laser shape through the grown layers. A schematic of the resulting "vertical waveguide" is shown in Fig. 3(b). The original MBE-grown laser material consists of a stack of layers with large compositional changes, and nonselective chemical "mesa" etching can only be applied to structures with widths above $20 \mu \mathrm{m}$. Microfabrication of smaller waveguided lasers thus relies on ion-assisted processes, such as reactive ion etching (RIE) or chemically assisted ion beam etching (CAIBE). With these anisotropic etching techniques, the sizes of electrically pumped lasers have been reduced to $1.5 \mu \mathrm{m}$ in diameter [Fig. 3(a)] [2]. This vertical waveguide geometry results in a large surface-to-volume ratio and substantial sidewall ion damage produced by exposing the sidewalls of such structures to the ion beam and to sidewall oxidation [53]. Another major problem of this design lies in the poor heat sinking of the laser cavity. Therefore, in pulsed operation, we typically observe increased threshold current density in devices below $10 \mu \mathrm{m}$ in diameter, whereas the total threshold current increases below $3 \mu \mathrm{m}$. However, in spite of these limitations, threshold currents as low as $0.8 \mathrm{~mA}$ have been measured on chemically treated vertical waveguide microlasers [2].

We have also isolated lasers by only defining the top mirrors and the lasing cavity [Fig. 4(a)] [18]. This requires only half the etch depth, results in better heat sinking of the laser cavity, and leads to improved $\mathrm{CW}$ laser performance. However, diffraction losses prevent us from arbitrarily decreasing the sizes of active devices much below $5 \mu \mathrm{m}$. Since, in this structure, the Si-doped mirrors are still intact and can be used as the bottom contact, this structure is particularly applicable to integrating microlasers into matrix-addressable arrays. Alternatively, we can use ion implantation to selectively shut off electrical conductivity in the $\mathrm{p}$-doped top mirror, thereby producing the gain-guided structure shown in Fig. 5(a) [26]-[31]. This is accomplished by proton bombardment or ion implantation of heavier species. The ion damage provides a "cloud" of disrupted material underneath the mask, which limits the resolution of the pattern transfer. Again, diffraction losses limit the ultimate size of structures. However, since the sidewalls of the quantum wells are not exposed to atmosphere in this geometry, surface recombination and cavity heating are reduced, resulting in better $\mathrm{CW}$ performance [28]. There are also processing advantages to retaining the surface planarity using the ion implantation process, especially for complex fabrication schemes involving large arrays. Finally, combinations of ion etching and ion implantation have also been employed 


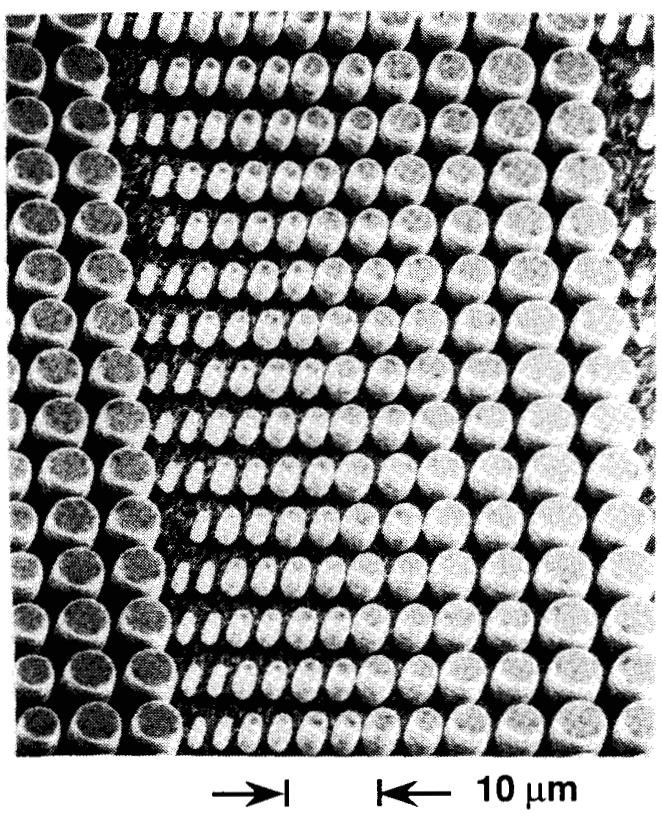

(a)

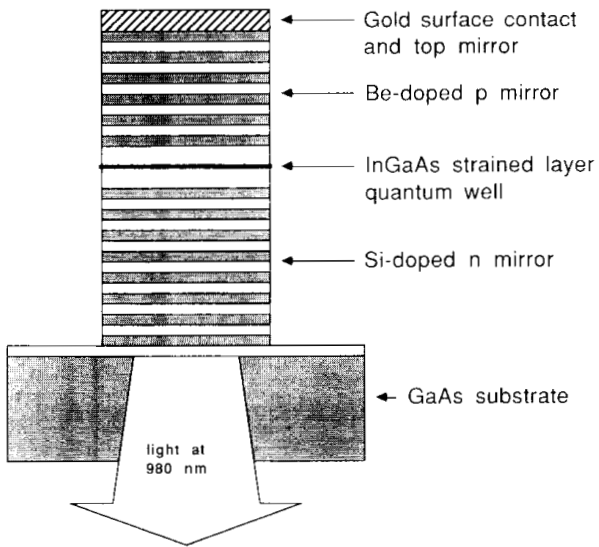

1. Vertical Waveguide Structure.

(b)

Fig. 3. (a) and (b) SEM micrograph and corresponding schematic of ion beam etched microlasers with diameters ranging from 1 to $5 \mu \mathrm{m}$.

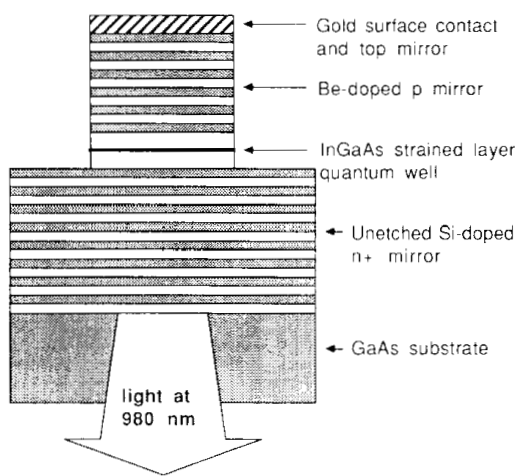

(a)

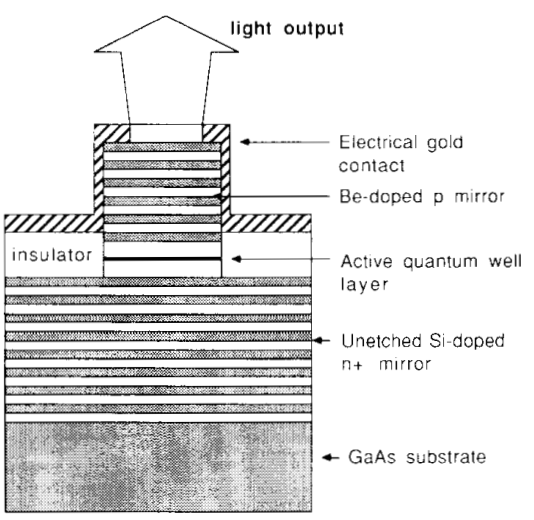

(b)

Fig. 4. (a) and (b) Schematics of front and back emitting microlasers defined by etching through the active region.

to avoid surface recombination and still limit the diffraction losses from small lasers [18]

\section{B. Ion Implantation and Masks}

Ion implantation has been used to produce implantation damage to define a limited conducting region in the active $\mathrm{p}-\mathrm{n}$ junction. The depth of the implantation depends on the ion mass and energy. In order to selectively implant $\mathrm{H}^{+}$to a depth of $2.5 \mu \mathrm{m}$ in AlGaAs, ion energies of 300 $\mathrm{keV}$ at a dose of $2.5 \times 10^{14} \mathrm{~cm}^{-2}$ are required [26]-[30]. To protect the conducting active laser region during this implantation, approximately $6 \mu \mathrm{m}$ of photoresist mask is required. This thick layer of photoresist is generally defined with a tri-level resist scheme, which has also been used to lift off a self-aligned p-type $\mathrm{Au}-\mathrm{Zn}$ contact [30]. These top surface-emitting lasers, schematically drawn in Fig. 5(b), are then annealed both to alloy in the contact and to anneal the slight damage in the upper layers, thus reducing the surface resistance. The key to processing these ion-implanted lasers lies in the fabrication of an appropriate implantation mask, and choosing the correct implantation species. 


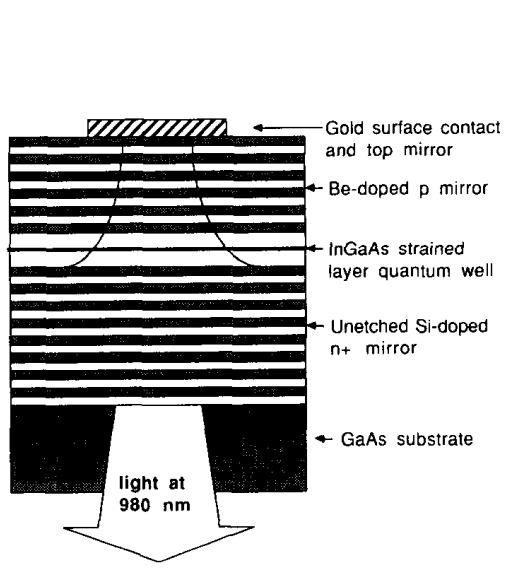

(a)

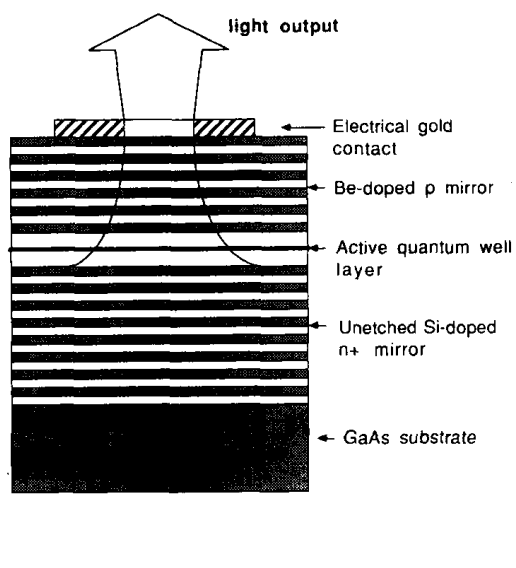

(b)

Fig. 5. (a) and (b) Schematics of front and back surface-emitting microlasers defined by ion implantation and gain guiding.

Masks used for ion etching and ion implantation have to satisfy fundamentally different requirements. Ion etch masks require good chemical stability of the mask material in the reactive etch chamber atmosphere, resulting in a good "selectivity" of the semiconductor material etching rate over the mask erosion rate. Ion implantation masks, on the other hand, should provide a large cross section to high-energy ions bombarding the material, and are typically much thicker. Metal masks are preferred for both cases, and can be used in structures where light is emitted out the substrate and through the back of the wafer [2], [16]-[19], [23], [24]. Nickel and chromium are particularly good CAIBE masks [54], whereas gold and tungsten are generally used for ion implantation. If laser emission is required from the surface of the wafer [Fig. 4(b) or 5(b)], removable masks have to be used with multilevel lithography. For ion implantation, such a mask stack can consist of $0.3 \mu \mathrm{m}$ of $\mathrm{SiO}_{2}, 6 \mu \mathrm{m}$ of hard-baked $\left(200^{\circ} \mathrm{C}\right.$, $1 \mathrm{~h})$ photoresist, $0.1 \mu \mathrm{m}$ of evaporated $\mathrm{Cr}$, and thin positive photoresist. In this fabrication scheme, the $\mathrm{Cr}$ layer is defined by wet etching using the top photoresist mask, and then this pattern is transferred by reactive oxygen etching through the $6 \mu \mathrm{m}$ implantation mask. The $\mathrm{SiO}_{2}$ layer is then removed in the contact area, the sample is implanted, and p-type contacts are evaporated. Finally, the hard-baked photoresist mask is stripped with photoresist stripper, simultaneously lifting off the contact metal [27]-[30]. Alternative single-level inorganic mask materials, such as silicon dioxide, silicon nitride, or tungsten, have also been employed to microfabricate lasers, and can subsequently be removed in a freon-oxygen dc plasma discharge.

\section{Ion Beam Etching}

GaAs-AlAs multilayers can be etched both by RIE and CAIBE with aspect ratios in excess of $10: 1$. To define VCSEL's, 3-7 $\mu \mathrm{m}$ of this DBR mirror material must be nonselectively removed. In general, chlorine-based reac- tive gases are ideally suited for such nonselective etching GaAs and AlAs layers [13]. The most important practical consideration during this etching process is to avoid buildup of aluminum oxide on the Al-containing layers, which reduces the etch rate and roughens the sidewalls of the etched microlasers. $\mathrm{BCl}_{3}$ mixtures are therefore often used to avoid oxide buildup during RIE [55], [56]. Another approach lies in increasing the etch rates, which also increases the etch rate selectivity of the AlAs-GaAs over the mask materials. We find that the high etch rates and anisotropy of CAIBE [57] makes it ideal for microfabricating of vertical-cavity optical devices. In our system, a Kaufman ion source is used to generate ion beams of $\mathrm{Xe}^{+}$ with energies between 500 and $1000 \mathrm{eV}$. The inert gas flow is regulated with a mass flow controller to $4.5 \mathrm{sccm}$ for $\mathrm{Xe}$, and the sample surface is exposed to $\mathrm{Cl}_{2}$ flux of approximately $10 \mathrm{sccm}$ which locally increases the sputter yield.

For any combination of ion energy, flux, and sample surface temperature, the partial pressure of reactive gas $\left(p_{\mathrm{Cl}_{2}}\right)$ must be optimized for maximum anisotropy and etch rate [19]. Generally, if $\left(p_{\mathrm{Cl}_{2}}\right)$ is too low, angled sidewalls result and trenches are formed next to the etched microstructures. Conversely, when $\left(p_{\mathrm{Cl}_{2}}\right)$ is too high, undercutting of the mask is evident. If the etching process is interrupted, a step results in the sidewall profile. Such a step is attributed to the oxidation of AlAs mirror layers forming $\mathrm{Al}_{2} \mathrm{O}_{3}$, which then acts as an ion etch mask.

High etch rates are needed to etch deep features, such as the $5.5 \mu \mathrm{m}$ microlaser structures, and still retain the necessary vertical sidewall profile. In CAIBE, fast and nonselective etching can be obtained by increasing the ion energies above $500 \mathrm{eV}$. However, at such high ion energies, ion damage can introduce recombination and scattering centers close to the etched vertical sidewalls [58], [59]. To microfabricate low-threshold lasers on the $<5$ $\mu \mathrm{m}$ scale, we therefore not only need to control the sidewall smoothness and the anisotropy of the microfabri- 
cated structures, but we also have to minimize the extent of the ion-induced damage to the structure sidewalls. In CAIBE systems, a decrease in the ion energies reduces such damage, but also causes a deterioration of the anisotropy. Instead, we have selected a heavy ion milling species, $\mathrm{Xe}^{+}$, which, with a lower velocity, reduces the ion damage while still producing the required etch rate and anisotropy [19].

\section{Packaging into Arrays}

The MBE-grown laser material and the laser definition techniques described in the previous subsections allow us to produce many nearly identical laser elements. This attribute of microlasers was used to package these devices into individually addressable arrays. These fall into two categories: 1) independently addressable arrays in which a separate contact made to each array member, and 2) matrix-addressable arrays in which contacts are made to columns and rows only. Ion implantation is fundamentally planar, facilitating the metallization steps needed to provide e.ectrical contact to the lasers. When ion beam etching is used, material surrounding each laser is removed, necessitating replanarization. To date, both independently addressable [60], [61] and matrix-addressable [62], [63] arrays, using the proton implantation process for the laser definition, have been successfully designed, fabricated, and tested. Fig. 6 shows a top view of an $8 \times 8$ independently addressable VCSEL array. The top portion of Fig. 7 shows schematically how the matrixaddressing scheme is incorporated into the VCSEL wafer. The fabrication of this particular array requires a combination of both ion implantation and etching techniques. The bottom of Fig. 7 shows a top view of a $32 \times 32$ array formed in such a manner. This matrix-addressable array contains $20-\mu \mathrm{m}$ diameter VCSEL's, fabricated on a 100 $\mu \mathrm{m}$ pitch. Including the bond pads at the perimeter, this 1024-laser array occupies $\sim 4 \mathrm{~mm} \times 4 \mathrm{~mm}$ of wafer area.

In Fig. 8, we schematically describe the processing steps involved in fabricating a matrix-addressable array of surface-emitting lasers when ion etching is chosen as the definition step. First, the individual laser elements are defined by etching through the active layer, using photoresist as an etch mask. Then, trenches are etched to define the bottom (n-type) contact, again using photoresist as an etch mask. Polyimide is spun onto this structure to fill these trenches, and provide an insulating layer between the $\mathrm{n}$ and $\mathrm{p}$ contacts. SEM micrographs of a matrixaddressable array after oxygen plasma etching of the polyimide to expose the upper laser contact is shown in Fig. 9(a). Following this procedure, the laser definition mask is again used to cover the top contacts with photoresist. Then, gold is angle evaporated to establish the $p$ contact, and lifted off from the laser tops. The last lithography step involves ion milling of the gold into stripes to define the top contact bars followed by oxygen RIE etching to expose the bottom contacts. The completed matrix-addressable device is shown in Fig. 9(b), where 1024

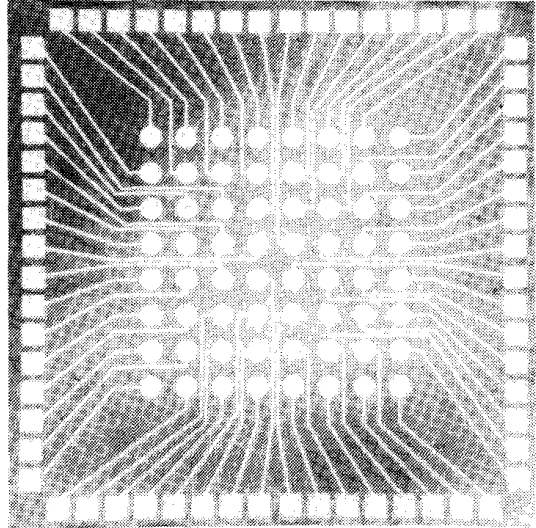

Fig. 6. Top view of an $8 \times 8$ independently addressable vertical-cavity surface-emitting laser array fabricated by ion implantation techniques. The lasers. $20 \mu \mathrm{m}$ in diameter, are in the center of the large circular contact pads.
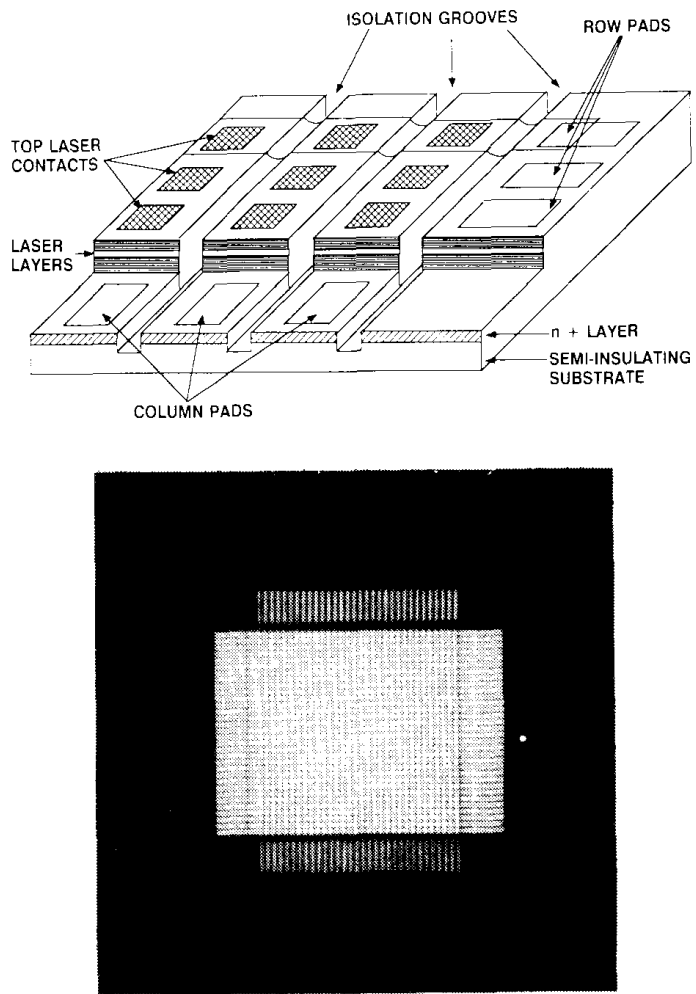

Fig. 7. Upper half shows the schematic of a matrix-addressable verticalcavity surface-emitting laser array requiring a combination of etching and ion implantation techniques. The lower portion is a top view of such a matrix-addressable $32 \times 32$ surface-emitting laser array. Lasers are $20 \mu \mathrm{m}$ in diameter, separated by $100 \mu \mathrm{m}$. Bond pads around the perimeter provide for contact to the $n / p$ (rows/columns) side of the devices.

$20 \mu \mathrm{m}$ wide elements are separated by $50 \mu \mathrm{m}$ center-tocenter spacing and fit into a $2.3 \mathrm{~mm} \times 2.3 \mathrm{~mm}$ area. A simpler air-bridging procedure has allowed us to define an $8 \times 8$ matrix of independently addressable lasers, 

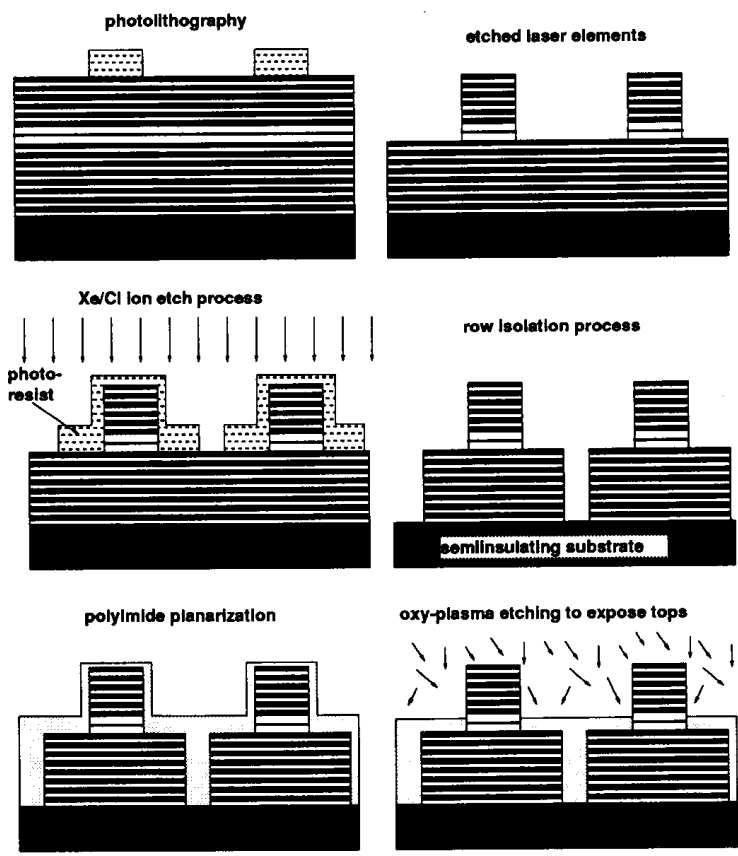

oxy-plasma etching to expose tops

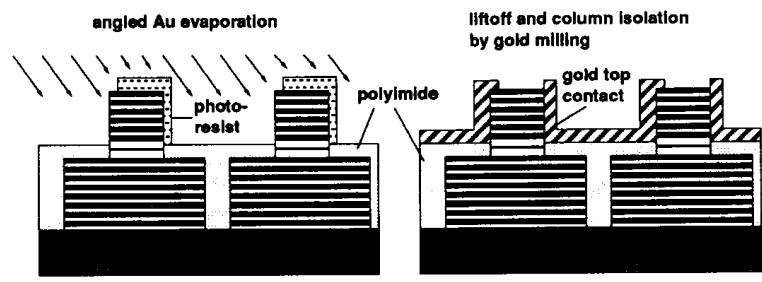

Fig. 8. One of the processing sequences employed to define a matrix-addressable microlaser array by ion etching.

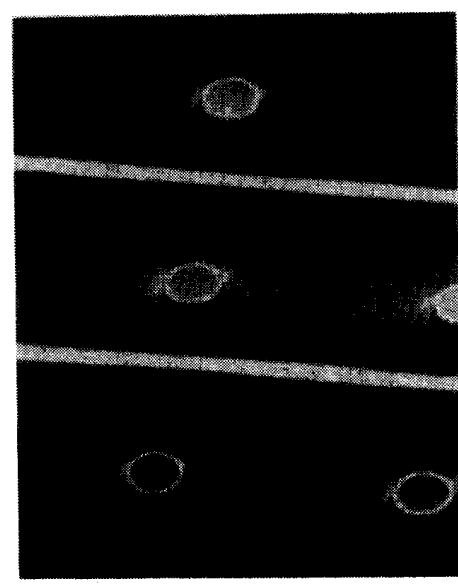

(a)

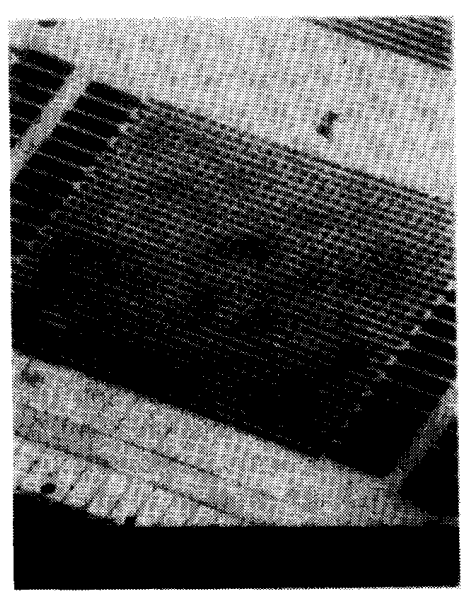

(b)

Fig. 9. (a) and (b) SEM images of $32 \times 32$ matrix-addressable laser array after polyimide planarization and after complete processing. 
which in this case only share the bottom (n-type) contact, and require individual $\mathrm{p}$ contacts.

\section{E. Ultrasmall Devices}

Threshold currents of vertical cavity microlasers are dominated by the active volume and the surface recombination of carriers at traps formed by ion damage or surface oxidation. A wet chemical treatment [39] of the surface of a $5 \mu \mathrm{m}$ laser after ion etching was used to reduce the threshold current from $1.5 \mathrm{~mA}$ to $0.8 \mathrm{~mA}$ (Fig. 10). Even without surface passivation treatments, optically pumped SQW lasers have been fabricated to sizes of about $0.5 \mu \mathrm{m}$ in diameter. During the fabrication of these submicron laser structures, vertical, $7 \mu \mathrm{m}$ long waveguides have to be defined to confine the pumped light inside the mirror structure. The resulting lasers have aspect ratios of as high as 15:1, and are shown in Fig. 11. Electron beam lithography is typically used to define the masks used for the definition of such ultrasmall lasers, and high-resolution optically transparent etch masks, such as $\mathrm{AlSrF}_{2}$ [64] are used to define the individual elements.

Heating of the laser structures during the ion beam etching process is one of the many problems we encounter when defining such highly anisotropic devices. Although the substrate is heat sunk, these small structures can no longer be conductively cooled during the fabrication or during the measurement process. It is therefore critical that the sidewalls of such structures are exposed to the reactive gas for a minimal amount of time. and spontaneous chlorine etching of the semiconductor material is controlled. This is accomplished by etching at very high material erosion rates, or by cooling the substrate. If it is possible, through such passivation or regrowth techniques, to decrease the surface recombination rate of such structures, the sizes of individual laser elements can be further reduced by electron beam lithography [64], and very low threshold currents can be achieved.

\section{Characterization}

In this section, characteristics of surface-emitting lasers with few quantum wells are exclusively summarized and compared. They are $980 \mathrm{~nm}$ InGaAs surface-emitting lasers (three quantum wells and a single quantum well) and $850 \mathrm{~nm}$ GaAs (four quantum wells) top-surface-emitting lasers. Thresholds for the lasers under study are mostly on the order of $1 \mathrm{~mA}$. All experimental data shown here are obtained at room temperature.

The first InGaAs three quantum well (InGaAs 3QW) lasers [16] have bottom (output) mirrors with 20.5 pairs GaAs-AlAs quarter-wave stack and hybrid top (back) mirrors with 12 pairs GaAs-AlAs quarter-wave stack capped by Au film. In pulsed operation, threshold for the InGaAs $3 Q W$ laser is $-1.3 \mathrm{~mA}$ from a $3-\mu \mathrm{m}$ diameter deep-etched mesa as shown in Fig. 12. "Deep etched" is defined as when the etch depth is deeper than the bottom mirror such that complete optical guiding is achieved. Room temperature $\mathrm{CW}$ operation was observed from a $5-\mu \mathrm{m}$ diameter $10 \mathrm{~nm}$ InGaAs SQW laser etched to just below the active region [17] with $1.5 \mathrm{~mA}$ threshold. Chemical passivation decreased it to $1 \mathrm{~mA}$. In both cases,

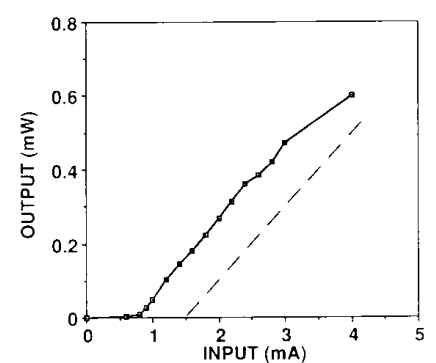

Fig. 10. Pulsed light versus current curve of a $5 \mu \mathrm{m}$ wide microlaser before (dashed) and after (nolid) passivation

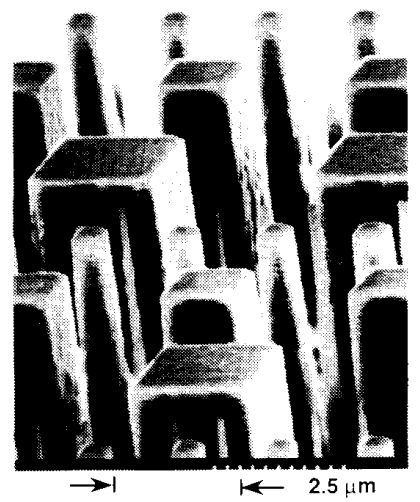

Fig. 11. SEM image of ultrasmall microlasers with widths down to 0.25 $\mu \mathrm{m}$ defined by ion beam etching.

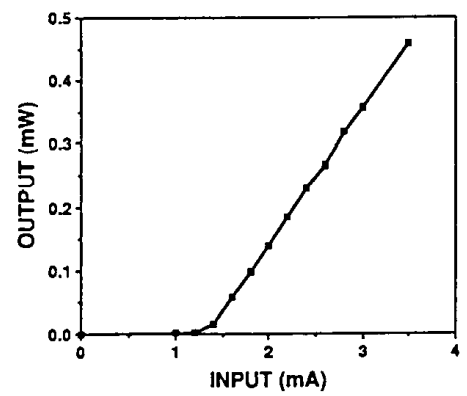

Fig. 12. Pulsed output light versus current in a $3-\mu \mathrm{m}$ diameter InGaAs 30 W laser.

the output power was limited due to ohmic heating and low differential quantum efficiency. The InGaAs SQW lasers have 23.5 and 15 pairs (plus $\mathrm{Au}$ ) of bottom and top mirrors to compensate for the reduced gain as compared to the $3 \mathrm{QW}$ InGaAs laser. The $\mathrm{CW}$ characteristics of InGaAs 3 QW structures are later improved [18] by shallow etching just above the active layer and implantation (half gain guiding and half index guiding) to $0.6 \mathrm{~mW}$ from a $10 \cdot \mu \mathrm{m}$ diameter laser by improving heat dissipation. Also by implantation isolation [26] of the InGaAs 3QW without etching, fully gain-guided planarized lasers are fabricated with similar performance characteristics. The Santa Barbara group reported the lowest threshold of 0.7 $\mathrm{mA}$ from a deep-etched $6 \mu \mathrm{m}$ square $8 \mathrm{~nm}$ InGaAs SQW device [24], at the expense of output power and quantum 
efficiency. The laser has 28.5 pairs and 23 pairs (plus $\mathrm{Au}$ ) of bottom and top mirrors, whose reflectivities are even higher than those of our design. In pulsed operation, peak powers are generally much higher than those of $\mathrm{CW}$ cases, indicating nontrivial thermal effects in CW operation. Differential quantum efficiencies are generally $5-30 \%$. The lasing wavelengths are between 940 and $980 \mathrm{~nm}$.

Top-surface-emitting GaAs four quantum well (GaAs 4QW) lasers [27]-[30] have all-MBE structures with 26.5-27.5 pairs of AlGaAs-AlAs quarter-wave layers bottom (back) and 19-20 pairs of AlGaAs-AlAs quarterwave layers top (output) mirrors designed at $850 \mathrm{~nm}$. Actual lasing wavelengths are $845-850 \mathrm{~nm}$. The characteristic reflectivity spectrum of an as-grown wafer is shown in Fig. 13. Since laser output in this case need not pass through the GaAs substrates, various wavelengths' lasers can be engineered at wavelengths opaque to bulk GaAs $(<880 \mathrm{~nm})$ without etching substrates. The deep-protonimplanted [65] GaAs 4QW lasers with current funneling generally have peak CW output powers of $>1.5 \mathrm{~mW}$ from all sizes tested $(10,15,20,30 \mu \mathrm{m})$. The maximum $\mathrm{CW}$ output power over $3.3 \mathrm{~mW}$ [30] was observed from 30$\mu \mathrm{m}$-diameter lasers in multitransverse mode operation. The thresholds are $2-10 \mathrm{~mA}$, depending on sizes. Typical optical and electrical characteristics of the lasers are shown in Fig. 14. CW slope efficiency as high as 1 $\mathrm{mW} / \mathrm{mA}$ was observed for a limited range above threshold, which corresponds to $\sim 70 \%$ differential quantum efficiency [29].

Threshold current densities for the InGaAs and GaAs lasers are comparable, ranging from $600 \mathrm{~A} / \mathrm{cm}^{2}$ to a few $\mathrm{kA} / \mathrm{cm}^{2}$, depending on the size of lasers, MBE growth accuracy, material quality, and design parameters. Generally, the operating current density increases with the reduction of sizes, mainly due to nonradiative surface recombination for index-guided structures or diffraction losses and other nonradiative recombinations for gainguided structures. These values are still much higher than the reported $60 \mathrm{~A} / \mathrm{cm}^{2}$ [66] for large area InGaAs edgeemitting lasers. Therefore, there is room for another order of magnitude improvement by proper passivation, wave guiding, and cavity design. Free carrier absorption in the highly Be-doped p-type mirror could be a limiting factor in approaching the cited current density of an edge-emitting laser. One of the main problems of the surface emitting lasers is their high resistance, resulting in high operating voltages. The reason lies in heterointerfacial potential barriers between GaAs (or AlGaAs) and AlAs quarter-wave layers, especially for holes in a p-type mirror as well as poor AlAs conductivity in the n-type mirror. For the InGaAs $3 \mathrm{QW}$ laser, graded AlGaAs superlattice layers [2], [23] are introduced between GaAs and AlAs quarter-wave layers in a p-type mirror as schematically shown in Fig. 1. In fact, these barrier-smoothing intermediate $\mathrm{AlGaAs}$ layers made possible the operation of deep-etched lasers in pulsed operation with biases ranging between 7-15 V, for 10-3 $\mu \mathrm{m}$ in diameter. Later, shallow etching with 5-10 $\mu \mathrm{m}$ diameters showed improved performance with a bias of 4-6 V, indicating significant resistance in the bottom n-type mirror as well. Lasers lat-

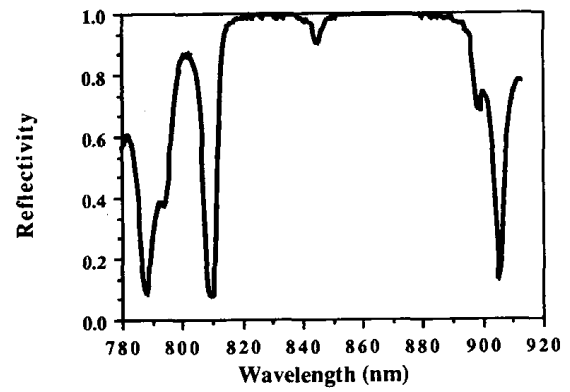

Fig. 13. A typical reflectivity spectrum of an as-grown GaAs $4 Q W$ laser wafer.

erally defined by proton implantation also operate with bias of approximately $4 \mathrm{~V}$. Generally, dynamic resistances above threshold are a few hundred to thousand ohms for $10-\mu \mathrm{m}$ diameter devices. All the InGaAs lasers studied by different groups also have $\mathrm{AlGaAs}$ graded superlattice to minimize resistances through $\mathrm{Be}$-doped p mirrors.

For the GaAs $4 \mathrm{QW}$ lasers, AlGaAs intermediate layers of double step (APA \#6) at only one interface [27], [29] and single step (ATT \#80) at two interfaces [28], [30] are used in the AlGaAs and AlAs quarter-wave p-type mirror as shown in Fig. 15. Lasers from APA \#6 have threshold voltages around 6-17 V, while lasers from ATT \#80 have threshold voltages around 4-5 V. Single-step AlGaAs intermediate layers (ATT \#80) function comparably to graded AlGaAs superlattices used in InGaAs lasers. The comparison study [34] on resistivities between AlGaAs step and $\mathrm{AlGaAs}$ superlattice intermediate layers also reported similar effectiveness. As the size of the gain-guided laser becomes smaller, propagation diffraction losses become more severe with the inverse fourth power of Gaussian beam radius. Therefore, gain-guided lasers much smaller than $5 \mu \mathrm{m}$ in diameter would be hard to realize, or would be inefficient [3], [18] if possible. But for sizes larger than $10 \mu \mathrm{m}$, top-surface-emitting lasers show good room temperature $\mathrm{CW}$ characteristics.

Dynamic characteristics were tested for InGaAs $3 \mathrm{QW}$ lasers and $\mathrm{GaAs} 4 \mathrm{QW}$ lasers using biased inductance mountings. When connected with a $50 \Omega$ resistor and a chip capacitor, an InGaAs $3 \mathrm{QW}$ laser showed $3 \mathrm{~dB}$ frequencies of $8 \mathrm{GHz}$ [2]. Gain switching of the same laser using $2 \mathrm{GHz}$ sinusoidal current generates gain-switched pulses with $\sim 25$ ps full width at half maximum. For GaAs $4 Q W$ lasers of $20 \mu \mathrm{m}$ in diameter, the $3 \mathrm{~dB}$ frequency is $3.7 \mathrm{GHz}$, which is limited by the parasitic capacitance and the $150 \Omega$ differential resistance. The GaAs $4 \mathrm{QW}$ laser has an $\mathrm{FM}$ response around $3 \mathrm{GHz}$ [67].

Surface-emitting lasers are generally linearly polarized. A detailed treatment of polarization and modal properties of VCSEL's formed by ion implantation can be found elsewhere in this issue [68]. In case of small deep-etched lasers less than $5 \mu \mathrm{m}$ in diameter, the polarization reflects asymmetry in the etched structure [2], [14]. For implanted (unetched) GaAs 4QW lasers with sizes larger than $10 \mu \mathrm{m}$, polarizations are along two cleavage axes of the GaAs crystal. Most lasers start lasing in a Gaussian 

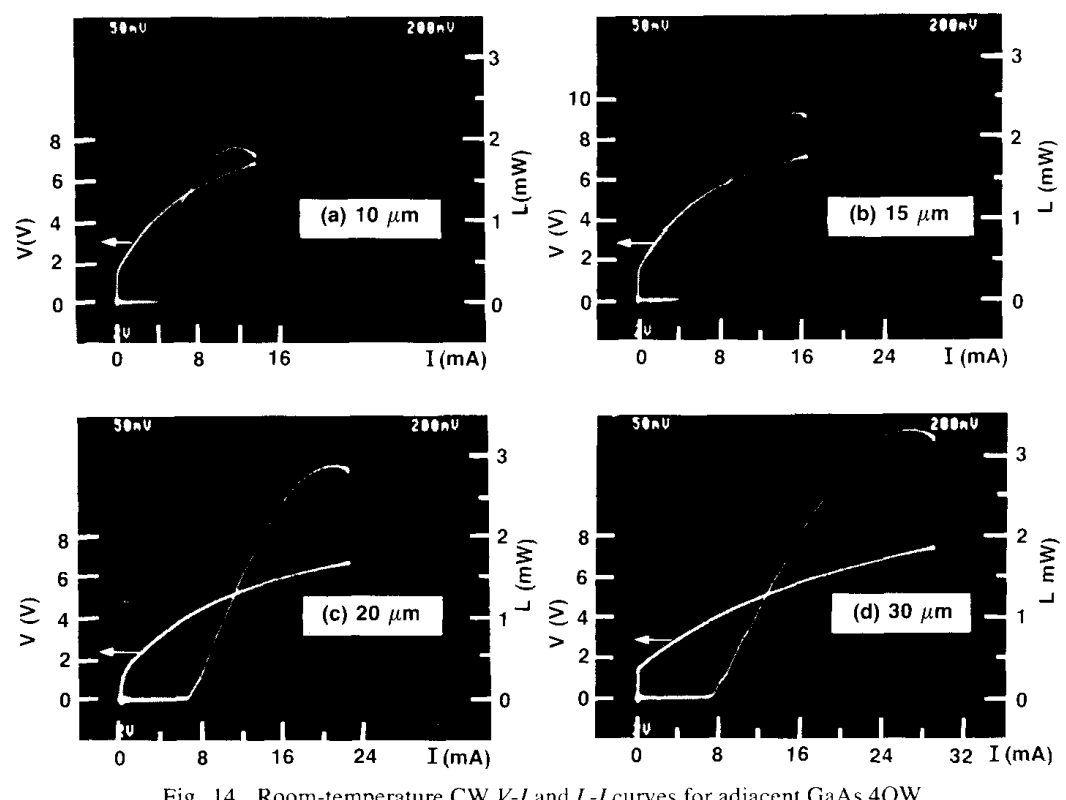

Fig. 14. Room-temperature CW $V-I$ and $L-I$ curves for adjacent GaAs $4 Q W$

lasers of different diameters.
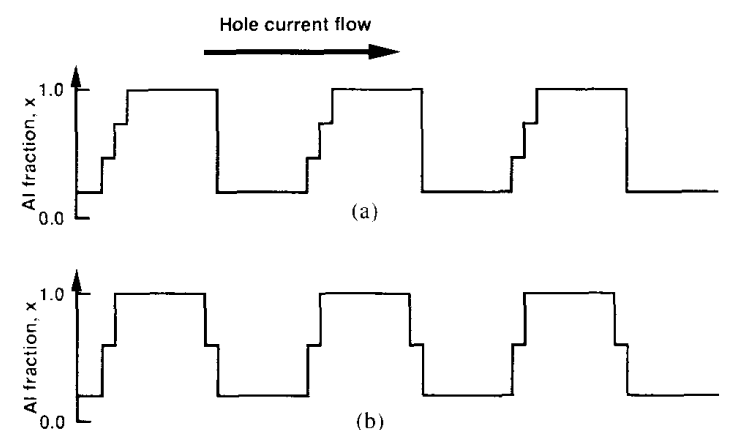

Fig. 15. Two configurations of p-type AlGaAs mirrors implemented for GaAs 4QW lasers. (a) APA \#6, and (b) AT\&T \#80.

mode. When operating gain-guided lasers in a fundamental Gaussian mode, Gaussian beam diameters at $1 / e^{2}$ intensity points are about half of the laser window sizes [29], resulting in twice the divergence of those calculated from a simple diffraction formula using aperture diameters. This seems to be the case for both GaAs $4 \mathrm{QW}$ and InGaAs $3 \mathrm{QW}$ gain-guided lasers. But high-order transverse modes up to $\mathrm{TEM}_{22}$ mode are reported [68] at well above the threshold from $20 \mu \mathrm{m}$ square gain-guided InGaAs lasers. Only a fundamental Gaussian mode was observed from small ( $<5 \mu \mathrm{m}$ square) deep-etched InGaAs lasers. For gain-guided GaAs 4QW lasers ( $>10 \mu \mathrm{m}$ diameter), development of higher order modes are observed from all sizes tested. Currently, the maximum $\mathrm{CW}$ output power in a fundamental mode is about $0.5 \mathrm{~mW}$. The onset of higher order modes generates noticeable kinks in $L-I$ characteristics curves. In principle, the high-order transverse modes are allowed for large lasers. It is not clearly understood, at present, but the onset of the higher order modes could be encouraged by spatially nonuniform ohmic heat- ing leading to slight thermal lensing effects over the laser aperture and/or gain saturation. Laser spectral linewidths are always spectrometer-limited when operating $\mathrm{CW}$ in a single transverse mode. For a limited power range $<0.06$ $\mathrm{mW}$, a linewidth-power product of $5 \mathrm{MHz} \mathrm{mW}$ was measured [24] by an interferometric method from an InGaAs SQW laser. Recently, from a $15 \mu \mathrm{m}$ diameter GaAs $4 \mathrm{QW}$ laser running at $0.3 \mathrm{~mW} \mathrm{CW}$, a Gaussian-mode spectral linewidth of $50 \mathrm{MHz}$ [69] was measured by optical heterodyne techniques using a commercial single-mode laser diode of $6 \mathrm{MHz}$ linewidth as a reference source. A similar linewidth was measured also from a longer vertical-cavity circular buried heterostructure surface emitting laser [7]. Preliminary data on lifetime testing [70] were collected from only a few GaAs 4QW samples. Laser driving currents were monitored under the constant output power condition $(0.8 \mathrm{~mW}, \mathrm{CW})$ at $40^{\circ} \mathrm{C}$. The data indicate $10000-20000 \mathrm{~h}$ of lifetime at $20^{\circ} \mathrm{C}$, which is still more than an order of magnitude shorter than that of commercial edge-emitting AlGaAs lasers. To be statistically meaningful, additional experimental data should be collected. Even with a high-reflectivity ( $>99 \%$ ) output mirror, the peak in-cavity optical intensity of a VCSEL is comparable to that of a typical edge-emitting laser, and the intensity at the laser output facet is much lower in the VCSEL than in the edge-emitting laser, taking the relatively large area of VCSEL's into account. VCSEL's could be as reliable as edge-emitting lasers.

\section{Vi. Conclusions}

It is expected that VCSEL performances will show significant advances in the next few years. A successful program of development must integrate all aspects including design, crystal growth, fabrication, and testing into one coherent effort. We hope that this presentation of these 
aspects in a single paper will aid readers in VCSEL development.

\section{ACKNOWLEDGMENT}

The authors would like to acknowledge the contributions of a large group of collaborators without whom this work would not have been possible, including S. L. McCall, B. Tell, K. F. Brown-Goebeler, R. E. Leibenguth, C. A. Burrus, R. S. Tucker, N. A. Olsson, J. M. Van Hove, Y. C. Chung, J. C. Jeong, V. D. Mattera, F. S. Choa, C. J. Sandroff, B. P. Van der Gaag, E. D. Beebe, M. Orenstein, A. C. Von Lehmen, and C. ChangHasnain. J. P. H. would like to acknowledge the extensive amount of work done by $\mathrm{L}$. Peterson in setting up the RHEED oscillation measurement system, without which the high degree of precision required for the growth of these structures would have been unachievable.

\section{REFERENCES}

[1] H. Soda, K. Iga, C. Kitahara, and Y. Suematsu, "GaInAsP/InP surface emitting injection lasers," Japan. J. Appl. Phys., vol. 18, pp. 2329-2330, Dec. 1979

[2] J. L. Jewell, Y. H. Lee, A. Scherer, S. L. McCall, N. A. Olsson, J. P. Harbison, and L. T. Florez, "Surface-emitting microlasers for photonic switching and interchip connections," Opt. Eng., vol. 29 , pp. 210-214, Mar. 1990

[3] K. Iga, F. Koyama, and S. Kinoshita, "Surface emitting semiconductor lasers," IEEE J. Quantum Electron., vol. 24, pp. 1845-1855, Sept. 1988.

[4] S. Uchiyama and K. Iga, "Two-dimensional array of GaInAsP/InP surface-emitting lasers," Electron. Lett., vol. 21, pp. 162-164, 1985.

[5] K. Iga, S. Kinoshita, and F. Koyama, "Microcavity GaAlAs/GaAs surface emitting laser with Ith $=6 \mathrm{~mA}$," Electron. Lett., vol. 23 , pp. 134-136, Jan. 1987

[6] F. Koyama, S. Kinoshita, and K. Iga, "Room-temperature continuous wave lasing characteristics of a GaAs vertical cavity surfaceemitting laser," Appl. Phys. Lett., vol. 55, pp. 221-223, 1989.

[7] H. Tanobe, F. Koyama, and K. Iga, "Spectral linewidth of AlGaAs/GaAs surface-emitting laser," Electron. Lett., vol. 25, pp. 1444-1446, Oct. 1989

[8] A. Ibariki, K. Kawashima, K. Furusawa, T. Ishikawa, T. Yamagushi, and T. Niina, "Buried heterostructure GaAs/AlGaAs distributed Bragg reflector surface emitting laser with very low threshold (5.2 $\mathrm{mA}$ ) under room temperature CW conditions," Japan. J. Appl. Phys., vol. 28, pp. L667-L668, Apr. 1989

[9] H. M Gibbs, S. L. McCall, T. N. C. Venkatesan, A. C. Gossard, and W. Wiegmann, "Optical bistability in semiconductors," Appl. Phys. Lett., vol. 35, pp. 451-453, 1979.

[10] A. Passner, H. M. Gibbs, A. C. Gossard, S. L. McCall, T. N. C. Venkatesan, and W. Wiegmann, "Ultrashort laser: Lasing in MBE GaAs layer with perpendicular-to-film optical excitation and emission," IEEE J. Quantum Electron., vol. QE-16, pp. 1283-1285, Dec. 1980.

[11] J. L. Jewell, Y. H. Lee, M. Warren, H. M. Gibbs, N. Peyghambarian, A. C. Gossard, and W. Wiegmann, "3-pJ, 82-MHz optical logic gates in a room-temperature GaAs-AlGaAs multiple- quantum-well etalon," Appl. Phys. Lett., vol. 46, pp. 918-920, Jan. 1985.

[12] J. L. Jewell, K. F. Huang, K. Tai, Y. H. Lee, R. J. Fischer, S. L. McCall, and A. Y. Cho, "Vertical cavity single quantum well laser," Appl. Phys. Lett., vol. 55, pp. 424-426, July 1989.

[13] J. L. Jewell, A. Scherer, S. L. McCall, A. C. Gossard, and J. H English, "GaAs-AlAs monolithic microresonator arrays," Appl. Phys. Lett., vol. 51, pp. 94-96, Apr. 1987.

[14] J. L. Jewell, S. L. McCall, Y. H. Lee, A. Scherer, A. C. Gossard, and J. H. English, "Lasing characteristics of GaAs microresonators," Appl. Phys. Lett., vol. 54, pp. 1400-1402, Apr. 1989.

[15] J. L. Jewell, S. L. McCall, A. Scherer, H. H. Houh, N. A. Whitaker, A. C. Gossard, and J. H. English, "Transverse modes, waveguide dispersion and $30 \mathrm{ps}$ recovery in submicron GaAs / AlAs microresonators," Appl. Phys. Lett., vol. 55, pp. 22-24, July 1989.

[16] J. L. Jewell, A. Scherer, S. L. McCall, Y. H. Lee, S. J. Walker, J. P. Harbison, and L. T. Florez, "Low threshold electrically-pumped vertical cavity surface emitting micro-lasers," Electron. Lett, vol. 25, pp. 1123-1124, Aug. 1989

[17] Y. H. Lee, J. L. Jewell, A. Scherer, S. L. McCall, J. P. Harbison and L. T. Florez, "Room-temperature continuous wave vertical cavity single quantum well microlaser diodes," Electron. Lett., vol. 25 , pp. 1377-1378, Sept. 1989.

[18] Y. H. Lee, J. L. Jewell, A. Scherer, B. Tell, K. Brown-Goebeler, J. P. Harbison, and L. T. Florez, "Effects of etch depth and ion implantation on surface emitting microlasers,"' Electron. Lett., vol. 25 pp. 225-226, Feb. 1989.

[19] A. Scherer, J. L. Jewell, J. P. Harbison, and L. T. Florez, Y. H. Lee, and C. J. Sandroff, "Fabrication of low threshold CW electrically pumped surface emitting microlasers," Appl. Phys. Lett., vol. 55, pp. 2724-2726, Dec. 1989.

[20] K. Y. Lau, P. L. Derry, and A. Yariv, "Ultimate limit in low threshold quantum well GaAlAs semiconductor lasers," Appl. Phys. Lett. vol. 52 , pp. 88-90, Jan. 1988 .

[21] Y.-H. Wu, M. Ogura, M. Wemer, and S. Wang, "New GaAlAsGaAs surface emitting laser diodes with lateral pumping structure,' Electron. Lett., vol. 23, pp. 123-124, Jan. 1987.

[22] R. Geels, R. H. Yan, J. W. Scott, S. W. Corzine, R. J. Simes, and L. A. Coldren, "Analysis and design of a novel parallel-driven MQWDBR surface-emitting-laser," in CLEO '88 Tech. Dig., Opt. Soc. Amer., Anaheim, CA, May 1988.

[23] R. S. Geels, S. W. Corzine, J. W. Scott, D. B. Young, and L. A. Coldren, "Low threshold planarized vertical-cavity surface emitting lasers,"' IEEE Photon. Technol. Lett., vol. 2, pp. 234-236, Apr. 1990.

[24] R. S. Geels and L. A. Coldren, "Submilliamp threshold vertical-cavity laser diodes," Appl. Phys. Lett., vol. 57, pp. 1605-1607, Oct. 1990.

[25] M. Y. A. Raja, S. R. J. Brueck, M. Osinski, C. F. Schaus, J. G. McInerney, T. M. Brennan, and B. E. Hammons, "Surface-emitting multiple quantum well GaAs/AlGaAs laser with wavelength resonant periodic gain medium," Appl. Phys. Lett, vol. 53, pp. 1678-1680, 1988.

[26] Y. H. Lee, B. Tell, K. F. Brown-Goebeler, J. L. Jewell, and J. V. Hove, "Top-surface-emitting GaAs four-quantum-well lasers emitting at $0.85 \mu \mathrm{m}, "$ Electron. Lett., vol. 26, pp. 710-711, May 1990.

[27] Y. H. Lee, B. Tell, K. F. Brown-Goebeler, J. L. Jewell, R. E. Leibenguth, M. T. Asom, G. Livescu, L. Luther, and V. D. Mattera, "High efficiency $(1.2 \mathrm{~mW} / \mathrm{mA})$ top surface-emitting GaAs quantum well lasers," Electron. Lett., vol. 26, pp. 1308-1309, Sept. 1990.

[28] Y. H. Lee, B. Tell, K. F. Brown-Goebeler, J. L. Jewell, C. A. Burrus, and J. V. Hove, "Characteristics of top-surface-emitting GaAs lasers," IEEE Photon. Technol. Lett., vol. 2, pp. 686-688, Sept. 1990.

[29] B. Tell, Y. H. Lee, K. F. Brown-Goebeler, J. L. Jewell, R. E. Leibenguth, M. T. Asom, G. Livescu, L. Luther, and V. D. Mattera, "High-power top surface-emitting GaAs quantum well lasers," Appl. Phys. Lett., vol. 57, pp. 1855-1857, Oct. 1990.

[30] K. Tai, R. J. Fischer, K. W. Wang, S. N. G. Chu, and A. Y. Cho, "Use of implant isolation for fabrication of vertical cavity surfaceemitting laser diodes," Electron. Lett., vol. 25, pp. 1644-1645, Nov. 1989.

[31] M. Orenstein, A. C. von Lehman, C. Chang-Hasnain, N. G. Stoffel, J. P. Harbison, L. T. Florez, E. Clausen, and J. L. Jewell, "Verticalcavity surface-emitting InGaAs / GaAs lasers with planar lateral definition," Appl. Phys. Lett., vol. 56, pp. 2384-2386, June 1990.

[32] J. L. Jewell, Y. H. Lee, S. L. McCall, J. P. Harbison, and L. T Florez, "High-finesse ( $\mathrm{Al}, \mathrm{Ga}) \mathrm{As}$ interference filters grown by molecular beam epitaxy," Appl. Phys. Lett., vol. 53, pp. 640-642, Aug. 1988

[33] L. M. Zinkiewicz, T. J. Roth, L. J. Mawst, D. Tran, and D. Botez, "High-power vertical-cavity surface-emitting AlGaAs/GaAs diode lasers," Appl. Phys. Lett., vol. 54, pp. 1959-1961, May 1989.

[34] K. Tai, L. Yang, Y. H. Wang, J. D. Wynn, and A. Y. Cho, "Drastic reduction of series resistance in doped semiconductor distributed Bragg reflector for surface emitting lasers," Appl. Phys. Lett., vol. 56, pp. 2496-2498, June 1990.

[35] D. Botez, L. M. Zinkiewicz, T. J. Roth, L. J. Mawst, and G. Peterson, "Low-threshold-current-density vertical-cavity surface-emitting AlGaAs/GaAs diode lasers," IEEE Photon. Technol. Lett., vol. 1, pp. 205-208, Aug. 1989.

[36] K. Tai, R. J. Fischer, C. W. Seabury, N. A. Olsson, T.-C. D. Huo, Y. Ota, and A. Y. Cho, "Room-temperature continuous wave vertical cavity surface emitting GaAs injection lasers," Appl. Phys. Lett., vol. 55 , pp. 2473-2475, Dec. 1989

[37] E. F. Schubert, L. W. Tu, R. F. Kopf, G. J. Zydzik, and D. G Deppe, "Low-threshold vertical cavity surface-emitting lasers with 
metallic reflectors," Appl. Phys. Lett., vol. 57, pp. 117-119, July 1990.

[38] J. I. Pankove, J. E. Bérkeyheiser, S. J. Kilpatrick, and C. W. Magee, "Passivation of GaAs surfaces,"' J. Electron. Material, vol. 12, pp. 359-370, Mar. 1983.

[39] C. J. Sandroff, M. S. Hedge, L. A. Farrow, C. C. Chang, and J. P. Harbison, "Electronic passivation of GaAs surfaces through the formation of arsenic-sulfer bonds," Appl. Phys. Lett., vol. 54, pp. 362 364,1989

[40] K. Tai, T. R. Hayes, S. L. McCall, and W. T. Tsang, "Optical measurement of surface recombination in InGaAs quantum well mesa structures," Appl. Phys. Lett., vol. 53, pp. 302-303, July 1988.

[41] T. Baba, T. Hamano, F. Koyama, and K. Iga, "'Spontaneous emission factor in micro-cavity DBR surface emitting laser," Euro. Conf. Opt. Commun., Amsterdam, The Netherlands, Sept. 1990, postdeadline Paper ThGi.3.

[42] Y. Yamamoto, S. Machida, W. Richardson, K. Igeta, and G. Bjork, "Squeezing and cavity quantum electrodynamics in GaAs quantum well lasers," presented at the Int. Quantum Electron. Conf., Anaheim, CA, May 1990, Paper QWC6.

[43] E. Yablonovitch, T. J. Gmitter, and R. H. Bhat, "Inhibited and enhanced spontaneous emission from optically thin AlGaAs/GaAs double heterostructures,"' Phys. Rev. Lett., vol. 61, pp. 2546-2549, Nov. 1988.

[44] S. Luryi, "Light emitting devices based on the real-space transfer of hot electrons," Appl. Phys. Lett., vol. 58, pp. 1727-1729, Apr. 1991

[45] A. Chailertvanitkul, K. Iga, and K. Moriki, "GalnAsP/InP surface emitting laser $(\lambda=1.4 \mu \mathrm{m}, 77 \mathrm{~K})$ with heteromultilayer Bragg reflector," Electron. Lett., vol. 21, pp. 303-304, Mar. 1985.

[46] K. Tai, S. L. McCall, S. N. G. Chu, and W. T. Tsang, "Chemical beam epitaxially grown InP/InGaAsP interference mirror for use near $1.55 \mu$ m wavelength,"' Appl. Phys. Lett. . vol. 51, pp. 826-827, Sept. 1987.

[47] P. A. Morton, D. L. Crawford, and J. E. Bowers, "Design of 1.3 $\mu \mathrm{m}$ GaInAsP surface emitting lasers for high bandwidth operation," Opt. Lett., vol. 15, pp. 679-681, 1990.

[48] D. G. Deppe, S. Singh, R. D. Dupuis, N. D. Gerrard, G. J. Zydzik, J. P. van der Ziel, C. A. Green, and C. J. Pinone, "Room-temperature photopumped operation of an InGaAs-InP vertical cavity surface-emitting laser," Appl. Phys. Lett., vol. 56, pp. 2172-2174, May 1990.

[49] S. T. Ho, S. L. McCall, R . E. Slusher, L. N. Pfeiffer, K. W. West, A. F. J. Levi, G. E. Blonder, and J. L. Jewell, "High index contras mirrors for optical microcavities," Appl. Phys. Lett., vol. 57, pp. 1387-1389, Oct. 1990

[50] D. M. Collins, "On the use of 'downward-looking' sources in MBE systems," J. Vac. Sci. Technol, vol, 20, pp. 250-251, Feb. 1982

[51] J. H. Neave, B. A. Joyce, P. J. Dobson, and N. Norton, "Dynamics of film growth of GaAs by MBE from RHEED oscillations," Appl. Phys. A, vol. 31, pp. 1-8, 1983.

[52] Y. H. Wang, K. Tai, Y. F. Hsieh, S. N. G. Chu, J. D. Wynn, and A. Y. Cho, "Observation of reduced current thresholds in GaAs/AlGaAs vertical-cavity surface emitting lasers grown on $4^{\circ}$ off-orientation (001) GaAs substrates," Appl. Phys. Lett., vol. 57, pp. 1613-1615, Oct. 15,1990 .

[53] A. Scherer, H. G. Craighead, M. L. Roukes, and J. P. Harbison, "Electrical damage induced by ion beam etching of GaAs," J. Vac. Sci. Technol., vol. B6, pp. 227-279, Jan./Feb. 1988

[54] A. Scherer and H. G. Craighead, "Fabrication of small laterally patterned multiple quantum wells, " Appl. Phys. Lett., vol. 49, pp. 1284$1286,1986$.

[55] A. Scherer, H. G. Craighead, and E. D. Beebe, "GaAs and AlGaAs reactive ion etching in $\mathrm{BCl}_{3} / \mathrm{Ar}$ mixtures," J. Vac. Sci. Technol., vol. B5, p. 1599, 1987

[56] K. P. Giapis, G. R. Scheller, R. A. Gottscho, W. S. Hobson, and Y $\mathrm{H}$. Lee, "Microscopic and macroscopic uniformity control in plasma etching," Appl. Phys. Lett., vol. 57, pp. 983-985, 1990.

[57] G. A. Lincoln, M. W. Geis, S. Pang, and N. Efremow, "Large area ion beam assisted etching of GaAs with high etch rates and controlled anisotropy," J. Vac. Sci. Technol., vol. B1, pp. 1043, 1983.

[58] P. Grabbe, A. Scherer, K. Kash, R. Bhat, J. P. Harbison, L. T. Florez, and M. Koza, "Photoluminescence measurement of sidewall damage in etched InGaAsP/InP and GaAs/AlGaAs microstructures," Material Res. Soc. Symp. Proc., vol. 144, p. 145, 1989.

[59] S. Pang, M. W. Geis, N. N. Efremow, and G. A. Lincoln, "Effects of ion species and adsorbed gas on dry etching induced damage in GaAs," J. Vac. Sci. Technol., vol. B3, p. 398, 1985.

[60] A. Von Lehmen, C. Chang-Hasnain, M. Orenstein, J. Wullert, N Stoffel, and J. P. Harbison, "Large electronically addressable VCSE laser arrays," presented at the Top. Meet. Opt. Multiple Access Networks, Monterey, CA, July 25-27, 1990.

[61] A. Von Lehmen, C. Chang-Hasnain, J. Wullert, L. Carrion, N. Stoffel, L. T. Florez, and J. P. Harbison. "Independently addressable InGaAs/GaAs VCSEL array," Electron. Lett., vol. 27, pp. 583595, Mar. 1991.

[62] M. Orenstein, A. C. Von Lehmen, C. Chang-Hasnain, N. G. Stoffel J. P. Harbison, L. T. Florez, J. R. Wullert, and A. Scherer, "Matrix addressable surface emitting laser array (MASELA), ' in Proc. Opt Soc. Amer. Annu. Meet., Orlando, FL. Oct. 16-20, 1989; see also, in Proc. Conf. Lasers Electro-Opt. (CLEO '90), Anaheim, CA, May 21-25, 1990, Paper CTuF3; see also, Electron. Lent., vol. 27, pp. 437-438, Feb. 1991

[63] A. Von Lehmen, J. Wullert, M. Orenstein, C. Chang-Hasnain, N. Stoffel, L. T. Florez, and J. P. Harbison, "Statistics and rastered operation of row/column-addressed VCSE laser array, " in Proc. 1990 Annu. Meet. Opt. Soc. Amer., Boston, MA, Nov. 4-9, 1990; also, submitted to IEEE Photon. Technol. Lett.

[64] B. P. Van der Gaag and A. Scherer, "Microfabrication below $10 \mathrm{~nm}$," Appl. Phys. Lett., vol. 56, pp. 481-483, Jan. 1990

[65] J. F. Ziegler, J. P. Biersack, and U. Littmark, The Stopping and Range of Ions in Solids, vol. 1. Elmsford, NY: Pergamon, 1984.

[66] H. K. Choi and C. A. Wang, "InGaAs / AIGaAs strained single quantum well diode lasers with extremely low threshold current density and high efficiency," Appl. Phys. Lett., vol. 57, pp. 321-323, July 1990.

[67] F. S. Choa, Y. H. Lee, B. Tell, T. L. Koch, C. A. Burrus, J. L. Jewell, R. E. Leibenguth, and G. Boyd, "Dynamic characteristics of a high-performance vertical-cavity surface-emitting laser," presented at the Conf. Opt. Fiber Commun. '91, San Diego, CA, Feb. 18-22. 1991.

[68] C. J. Chang-Hasnain, J. P. Harbison, G. Hasnain, A. Von Lehmen, L. T. Florez, and N. G. Stoffel, "Dynamic polarization and transverse mode characteristics of vertical cavity surface emitting lasers," IEEE J. Quantum Electron., this issue, , pp. 1368-1376.

[69] C. J. Chang-Hasnain, M. Orenstein, A. Von Lehmen, L. T. Florez, J. P. Harbison, and N. G. Stoffel, "Transverse characteristics of vertical cavity surface-emitting lasers," Appl. Phys. Lett., vol. 57, pp. 218-220, July 1990

[70] Y. C. Chung, private communication.

[71] J. C. Jeong, private communication.

Jack L. Jewell, photograph and biography not available at the time of publication.

J. P. Harbison, photograph and biography not available at the time of publication.

A. Scherer, photograph and biography not available at the time of publication.

Y. H. Lee, photograph and biography not available at the time of publication.

L. T. Florez, photograph and biography not available at the time of publication. 